\title{
Comparison of Patient Satisfaction Level and its Various Determinants in Public and Private Hospitals in Peshawar
}

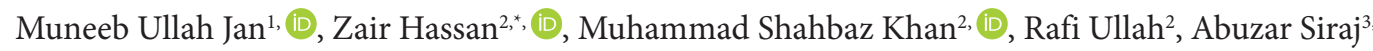 \\ ${ }^{1}$ Department of Medicine, Khyber Teaching Hospital, Peshawar, Pakistan \\ ${ }^{2}$ Department of Cardiology, Lady Reading Hospital, Peshawar, Pakistan \\ ${ }^{3}$ Department of Medicine, Hayatabad Medical Complex, Peshawar, Pakistan
}

\section{ARTICLE INFO}

\section{Article History}

Received 30 May 2020

Accepted 22 August 2020

\section{Keywords}

Patient satisfaction

public and private hospitals

finance

general satisfaction

\begin{abstract}
The satisfaction of the patients and its importance in modern medicine cannot be emphasized enough. It is a potential tool that can invariably give a look-in into the performance of a hospital itself and health professionals (either directly or indirectly). The purpose of this study was to evaluate patient satisfaction levels and determinants of patient satisfaction in public and private tertiary care health setting of Peshawar, Pakistan, where the concept of patient satisfaction and patient-oriented medical care has been more of a recent development compared with other parts of the world, and where it has not been able to establish itself as a critical factor among healthcare providers. A total of 200 patients (100 from private and 100 from public sector hospital) were given a standardized patient satisfaction questionnaire 18 through the convenience sampling technique. The result showed that most patients in the private sector were more satisfied with various aspects of medical care compared with patients in the public sector. Overall, $96 \%$ of patients in private hospitals were confident that the medical care they had been receiving was perfect compared with $86 \%$ of patients in the public sector. Moreover, $49 \%$ of patients in public hospitals and $84 \%$ in the private sector disagreed when questioned if they were dissatisfied with the medical care they had received. In conclusion, patients in the private sector were more satisfied with the healthcare services provided to them in most categories than patients in the public sector. However, patients in private hospitals were less confident in terms of accessibility and affordability than those of the public sector.
\end{abstract}

(c) 2020 Dr. Sulaiman Al Habib Medical Group. Publishing services by Atlantis Press International B.V. This is an open access article distributed under the CC BY-NC 4.0 license (http://creativecommons.org/licenses/by-nc/4.0/).

\section{INTRODUCTION}

One of the useful tools with which we can measure a health professional's performance is the extent to which the patients are satisfied with their treatment or attitude. The modern world has realized and implemented the concept of customer care and customer satisfaction. This has been reflected in the medical world as well. With modern evidence-based medicine and patient care as its two cornerstones, patient care involves a patient-centric approach, in which patient satisfaction from medical care plays an important role [1]. All of these factors account for a change in the paradigm shift in the orthodox manner with which patients are treated and cared for. Emphasis has been placed not only on curing the patient but more on a generalized basis in which other aspects of medical care, for example, patient satisfaction, are as important as the actual cure.

Various standardized surveys known as Patient Satisfaction Questionnaires (PSQ) have been designed to measure actual patient satisfaction levels. This approach uses a system of questions and marks to evaluate the level of the extent with which the patients are satisfied or dissatisfied, that is, PSQ3 and the modified shorter form PSQ18 [2], which have been used in studies conducted in various

"Corresponding author. Email: zair.hassan7272@gmail.com

Peer review under responsibility of the Dr. Sulaiman Al Habib Medical Group

Data availability statement: The data that support the findings of this study are available

from the corresponding author, $[\mathrm{ZH}]$, upon reasonable request. hospitals. However, patient satisfaction is a valuable tool and a benchmark in the West and is given its due importance both by hospitals and policymakers. There have been many studies conducted on this issue around the world [3]. Patient satisfaction depends on an array of factors [4]. In Pakistan, however, the concept of patient satisfaction and patient-oriented medical care is more of a recent development compared with other parts of the world, and to date it has not been able to establish itself as a critical factor among healthcare providers. However, the Pakistan Medical and Dental Council (PMDC) has incorporated some of it into the medical curricula. In Pakistan, several studies have been conducted, some of which have used standardized or tested PSQ, whereas others have used selfmade criteria [5]. A literature search showed a minimal amount of published material on this subject in Pakistan. To date, no published studies were carried out in this part of the country (Peshawar). The study was proposed to evaluate patient satisfaction level and its various determinants in public and private hospitals in Peshawar.

\section{LITERATURE}

The word hospital itself is an offshoot of a Latin word, which holds for both "guest" and "host," and this nature of warmth and cordial welcoming attitude is at the epicenter of this whole hospital experience [6]. The term patient satisfaction coincides with the development of the modern world. Various means have been used to define 
patient satisfaction. It is defined as the extent of one's experience compared with one's expectations [7]. Patient satisfaction is fast becoming a key requirement and an essential arm of this package of modern medical care and hospitals, and there is increasing evidence that patient satisfaction is being incorporated by hospitals into healthcare quality plans [8].

Various questionnaires have been designed for measuring patient satisfaction, including one questionnaire created by Picker Institute (Boston, MA, USA) and used by the National Institutes of Health (NIH) and Europe. Ware et al. [9] developed other forms of PSQ, with the latest one being a PSQ18 [10], which consisted of 50 questions, which in turn has subsequently been reduced to another short form. This PSQ18 consisted of 18 items.

Raheem et al. [11] studied private hospitals in Karachi, where they sampled patients from the city's five leading private sector hospitals [11], with an alpha score of 0.9 for their designed questionnaire. Their results showed that most of the patients were satisfied with several services offered in the various departments of the hospitals. More than $70 \%$ of patients were satisfied with the Outpatient Department (OPD), and ultrasound and emergency services available to them; $57-60 \%$ of patients were satisfied with the pharmacy and food services, and 61-70\% were satisfied with radiology, billing, blood bank, housekeeping, ward, and welfare services. A $p$-value of 0.01 was considered statistically significant in their analysis.

Irfan and Ijaz [12] from COMSATS University Lahore and Institute of Quality and Technology Management, University of Lahore, performed a similar study in which they measured differences in service quality of various public and private hospitals in Lahore. They used a SERVQUAL instrument score to gauge patient perception about multiple service quality dimensions in these hospitals [12]. For this purpose, they circulated about 500 questionnaires with 320 responses that were thought of as valid and eventually considered in the sample size data. Their results after applying Levene's test for $p$-value in all categories showed that private hospitals had significant levels of increased patient satisfaction, and a considerable difference existed between satisfaction levels of private and public hospitals.

Mostafa [13] conducted a cross-sectional study using the same SERVQUAL Scale in 2005. He collected data from 13 different hospitals in Egypt with a data sample of 332. He also reported similar results, wherein patients in the private sector were satisfied with various aspects of healthcare compared with patients in the public sector [13].

Shabbir et al. [14] studied various aspects of services provided by Pakistani hospitals and their impact on patient satisfaction. They based their research in Islamabad, collected data from multiple public and private sector hospitals, and developed their questionnaire using multiple scales. Their questionnaire's patient satisfaction aspect used four items adapted from the Kavanaugh et al. [15] study. Their results showed that patient satisfaction was higher in public hospitals than in private hospitals, with the mean of public hospitals measured at 3.52 and that of private hospitals at 3.04.

\section{RATIONALE OF THE STUDY}

Such a research study in the four premier tertiary care hospitals of Khyber Pakhtunkhwa (KPK) has not been done previously. This study could potentially point toward various discrepancies in inpatient care of both public and private hospitals.

\section{OBJECTIVES}

The objectives of this study were to: (1) check patient satisfaction levels in public and private hospitals using a modified PSQ (PSQ18) in inpatient and outpatient departments of these hospitals; (2) compare patient satisfaction levels in public and private hospitals; and (3) evaluate various modifying factors/determinants of patient satisfaction.

\section{MATERIALS AND METHODS}

\subsection{Study Setting}

This study was conducted in two private and public sector hospitals in their OPD-that is, NorthWest General Hospital, Rehman Medical Institute, Hayatabad Medical Complex, and Khyber Teaching Hospital of Peshawar, KPK-from June 1, 2019 to April 30, 2020. A standardized questionnaire was used, and survey forms were collected from about 100 patients from public and private sector hospitals. These four leading tertiary hospitals in Peshawar essentially provide similar services, and hence we wanted to examine and evaluate the various determinants of patient satisfaction in these hospitals.

\subsection{Study Design}

This investigation was designed as a comparative cross-sectional study.

\subsection{Sample Size}

Using the World Health Organization sample size calculator with a $6.93 \%$ margin of error and a 95\% confidence level and Peshawar's population as 4 million, the sample size was calculated to be 200. A total of 250 filled questionnaires were collected, out of which 50 were excluded from the final analysis owing to incomplete data.

\subsection{Selection Criteria}

The inclusion criteria were as follows: (1) all willing consenting patients; (2) those treated in the inpatient and outpatient departments of selected hospitals; (3) patients of all ages who were discharged from the OPD. The exclusion criteria applied to (1) all patients admitted to the intensive care unit and the cardiac care unit and (2) those who were noncooperative.

\subsection{Sampling Technique}

A convenience sampling technique was used to assess the required number of patients. 


\subsection{Data Collection Tool}

The patients were provided with a self-explanatory questionnaire (paper) and pen after consent has been properly obtained. Participation in the study was purely voluntary. The participants were approached in hospitals during their visit in the OPD from 9 AM to 2 PM. The survey (PSQ-18) is based on a standardized PSQ. The standardized questionnaire is divided into seven parts with questions ranging from general satisfaction to financial matters and interpersonal relations, etc. Every question in the survey had five options from strongly agree to strongly disagree (score ranging from 1 to 5). As the questionnaire was in English, and keeping the local scenario in mind, the survey was explained in the local language (Urdu and Pashtu) to every participant. The alpha score was 0.6 , which meant that our questionnaire was reliable.

\subsection{Data Analysis}

The data analysis was done using IBM SPSS version 21 (IBM Corporation, Armonk, NY, USA). Variables such as age were analyzed via mean and Standard Deviation (SD). Chi-square test was used to analyze the relationship between the categorical (nominal) variables. A $p$-value $<0.05$ was considered significant, and $95 \%$ was taken as confidence and $5 \%$ taken as the margin of error.

\subsection{Ethical Considerations}

The research protocol was reviewed and approved by the Institutional Ethical Committee of Hayatabad Medical Complex, Peshawar, Pakistan (Ref number: 2116-HMC/MAW).

\section{RESULTS}

A total of 200 patients (100 from private and 100 from public sector hospitals) were given a standardized PSQ 18 and were considered for final analysis. The participants' mean age $( \pm \mathrm{SD})$ was $45.01 \pm$ 14.89 and $37.87 \pm 16.01$ years in public and private hospitals, respectively. More married patients were treated in public hospitals $(43 \%)$ than in private hospitals (31\%). The sociodemographic characteristics of participants are given in Table 1.

Table 1 Sociodemographic details of the participants

\begin{tabular}{lcc}
\hline Characteristics & Public sector & Private sector \\
\hline Age (years) & & \\
Mean \pm SD & $45.01 \pm 14.89$ & $37.87 \pm 16.01$ \\
Sex $(n)$ & 56 & 46 \\
Male & 44 & 54 \\
Female & & \\
Marital status $(n)$ & 14 & 36 \\
Single & 86 & 82 \\
$\quad$ Married & & \\
Education $(n)$ & 81 & 61 \\
Illiterate & 1 & 2 \\
$\quad$ Under matric & 18 & 37 \\
$\quad$ Matric & & \\
\hline
\end{tabular}

\section{DISCUSSION}

The modern world and the times that we live in have revolutionized our society, because of the presence of various modalities and agencies of information. The sine qua non being the media, all this has led to greater awareness. The advent of the internet has also led to the new archetype, in which patients use the modalities as mentioned above and have some beforehand knowledge of their disease. All of this, combined with the 21 st century phenomenon of consumerism, has spellbound the healthcare industry. The importance of matching the patients' expectations has increased by many folds and given birth to the idea of patient satisfaction.

Our research was based on the basic idea of comparing various determinants of the patient satisfaction level in four premier tertiary care hospitals in Peshawar (two public hospitals and two private hospitals). We did a thorough search and selected a standardized PSQ18, which itself had seven sections. On application of the reliability test, the alpha score was found to be 0.71 .

Our results showed that in the category of general satisfaction when asking the patients if the medical care they had been receiving was perfect, 86 out of 100 patients in public sector hospitals agreed or strongly agreed. The total increased to 96 in the case of private hospitals (Figure 1). Similarly, $84 \%$ of private hospital patients and $49 \%$ of public hospital patients rebuffed the notion of being dissatisfied with some aspects of the medical care they had been receiving (Figure 2).

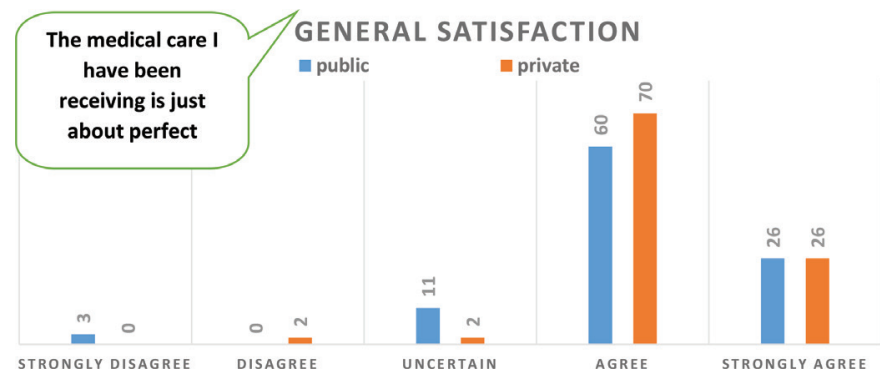

Figure $1 \mid$ Patients were asked if the medical care they had been receiving is just about perfect. Out of 100 patients in public sector hospitals, 60 agreed, 26 strongly agreed, and 11 were uncertain. Meanwhile, out of 100 patients in the private sector, 70 agreed, 26 strongly agreed, and none disagreed or strongly disagreed.

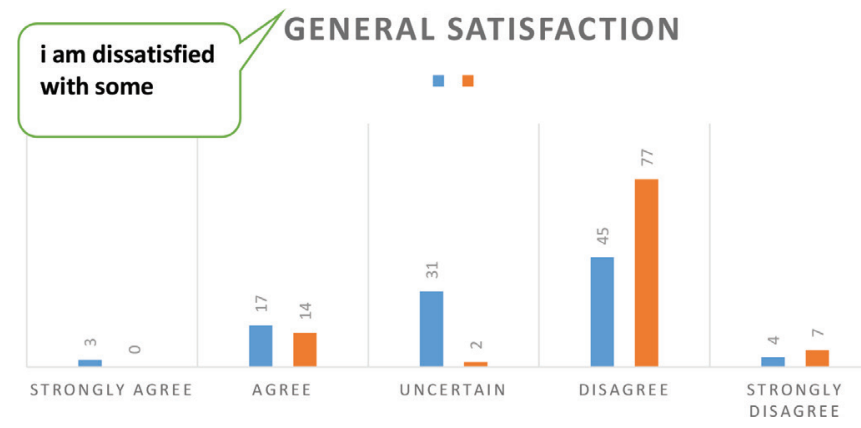

Figure $2 \mid$ Patients were asked if they were dissatisfied with certain aspects of the medical care they had been receiving. Seventy-seven patients in the private sector disagreed, seven patients strongly disagreed, and only 17 patients agreed. In the public sector, only 45 patients disagreed, and four patients strongly disagreed. 
The overall satisfaction percentage in the general satisfaction category was relatively high in public and private sector hospitals. A similar research was done by Jawaid et al. [16], who used a 10-point anchored scale proforma in the surgical OPD of Civil Hospital, Karachi. They ranked general satisfaction at 75\%, whereas in another research carried out by Khattak et al. [17] general satisfaction was pegged at $68 \%$ in the private sector and $46 \%$ in the public sector.

The next section was technical data. When asked if they ever wondered if the diagnosis of their doctors were correct, the patients gave interesting results as the majority, $49 \%$ of private-sector patients, presented an affirmative response. In contrast, most patients in the public sector were uncertain and could not swing either way (Figure 3). The percentage stood out at $47 \%$. The study conducted by Imam et al. [5] was carried out in a major tertiary care hospital in Karachi, the Aga Khan Teaching Hospital. The oncology department showed that $<1 \%$ of patients said that they did not have trust or confidence in their doctors. About $12.5 \%$ trusted their medical care providers to a limited extent. Still, it is worth mentioning that Imam et al. [5] used a validated PSQ set up by the Picker Institute for the NIH and Europe.

In another question of the same section, the researchers asked the patients if the doctors were careful to check everything when examining them. To this question, most patients both in the public and

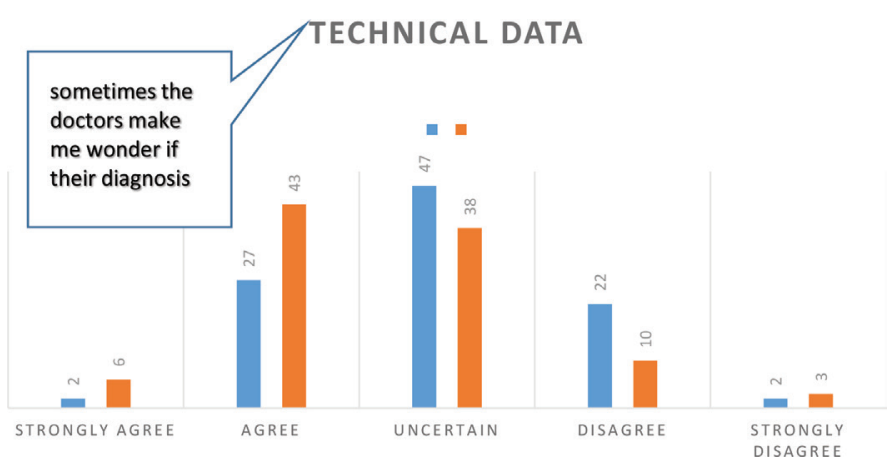

Figure 3 When patients were asked whether they sometimes wonder if their doctor's diagnosis was correct, in the public sector hospitals, 47 patients were uncertain, 22 patients disagreed, and 27 patients agreed. Meanwhile among patients in private hospitals, 43 agreed, 38 were undecided, and only 10 disagreed.

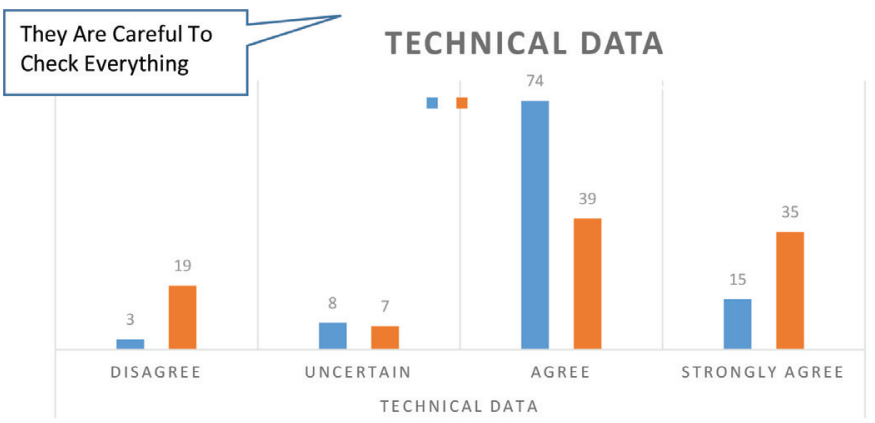

Figure $4 \mid$ Seventy-four patients in public hospitals agreed, and 15 patients strongly agreed when inquired if they thought the doctors were careful to check everything when treating them-compared with 19 patients who disagreed and 39 patients agreed and 35 patients strongly agreed in private hospitals. private sectors gave an affirmative reply, with a total of $89 \%$ in the public sector (strongly agree or agree) and $74 \%$ in the private sector (strongly agreed or agree) (Figures 4 and 5).

In sections of interpersonal relations and communication, there were mixed results. In terms of interpersonal relationships, 75\% of patients in private hospitals either agreed or strongly agreed when they were asked if their doctors treated them in a friendly manner or were courteous. Meanwhile, in the public sector, the percentage was $85 \%$. The cumulative percentage of both sets of hospitals was $80 \%$ (Figures 6 and 7 ).

In the communication section, patients were asked if their doctors were good at explaining medical tests. To this question, 59\% of patients in the public sector agreed compared with $58 \%$ of patients in the private sector. When patients were asked if doctors sometimes ignored what they (patients) told them, most patients in public sector hospitals agreed (i.e., 48\%). By contrast, most patients

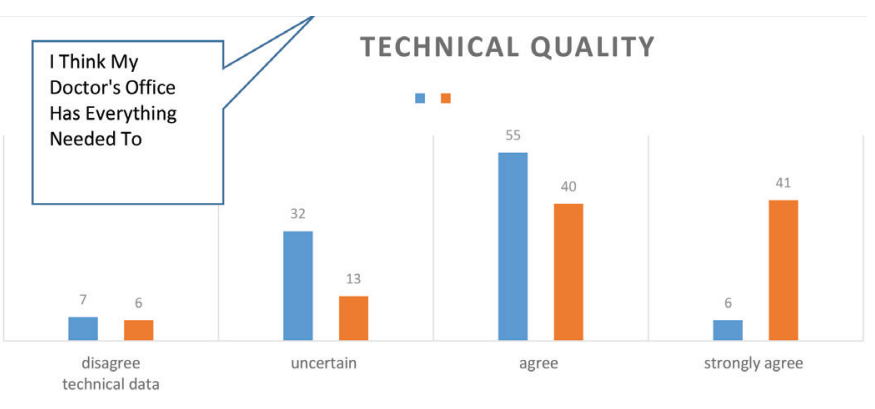

Figure 5 Eighty-one patients in private hospitals either agreed or strongly agreed when inquired if they thought their doctor's office had everything needed to provide them with complete care, compared with 61 patients who agreed or strongly agreed in the public sector.

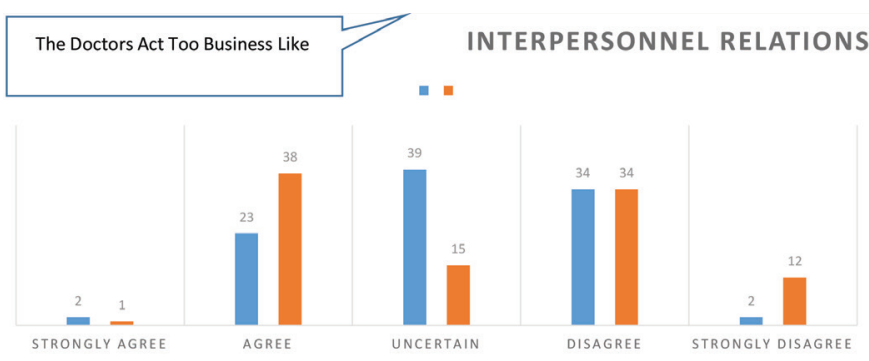

Figure 6 In private hospitals, 46 patients either disagreed or strongly disagreed when asked if their doctors were more business-like and impersonal toward them than the 36 patients in the public sector who either disagreed or strongly disagreed.

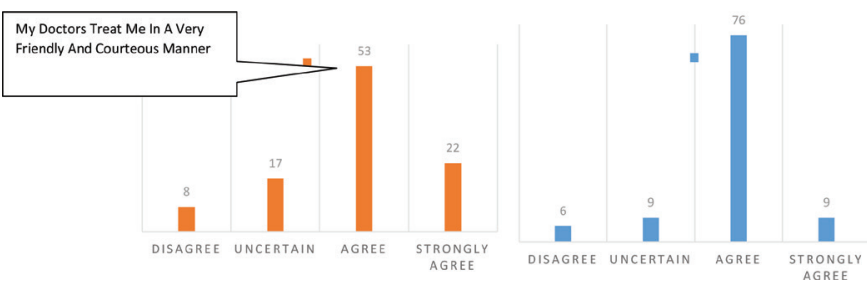

Figure $7 \mid$ Overall, $8 \%$ of patients in private hospitals and $6 \%$ of patients in public hospitals disagreed when asked if their doctors treated them amicably and courteously, whereas $75 \%$ of patients in private and $85 \%$ in public hospitals gave a positive response to the proposition. 
in private sector hospitals disagreed with this question-48\% of patients, including the 5\% who strongly disagreed (Figures 8 and 9).

Patients were also asked if they had to pay for medical care more than they could afford in the finance section. Results showed that $62 \%$ of patients in public sector hospitals agreed, whereas $89 \%$ of patients in private sector hospitals gave an affirmative answer. Qidwai et al. [18] carried out a similar research, in the family practice clinic at the Agha Khan University Teaching Hospital, and their results indicated that $62 \%$ of patients were satisfied with the consultation charges [18], whereas in the research carried out by Imam et al. [5], 40\% of patients were worried about how much they would have to pay during their stay (Figure 10).

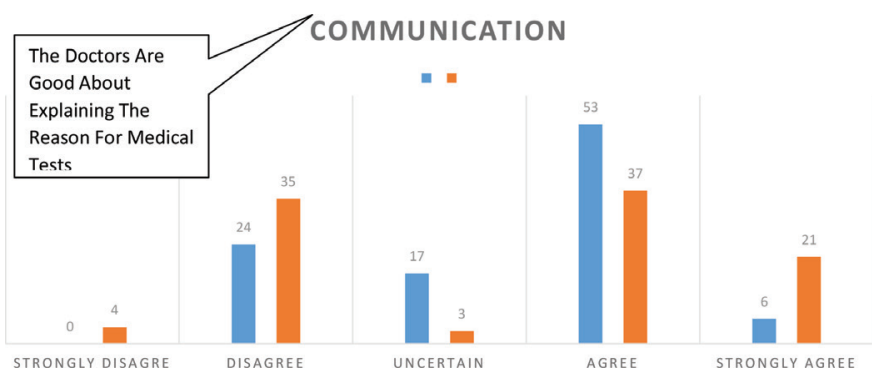

Figure 8 In public sector hospitals, 59 patients agreed or strongly agreed to the proposition that the doctors adequately explained the reason for medical tests, whereas 58 patients in private hospitals agreed and 35 patients disagreed.

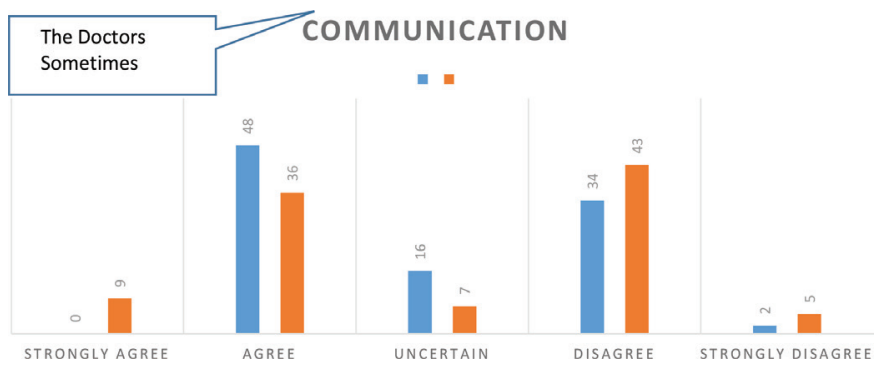

Figure 9 Thirty-four patients in the public sector and 43 patients in the private sector disagreed that doctors sometimes ignored what the patients told them, whereas 48 patients in the public sector and 45 patients in the private sector agreed to the same proposition.

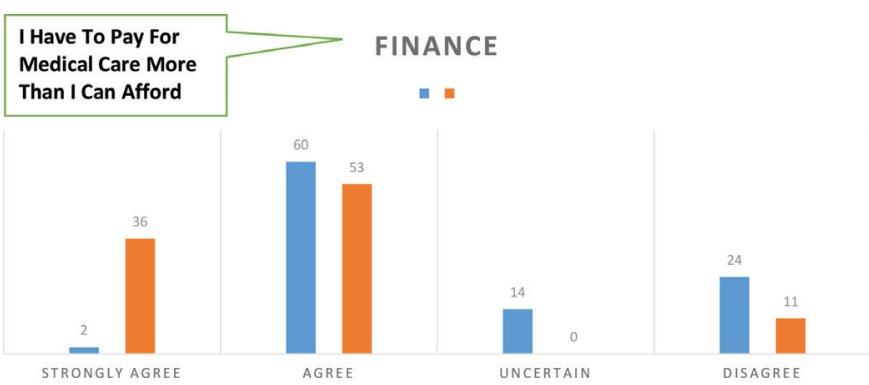

Figure 10 The majority of patients in private hospitals agreed that they had to pay for medical care more than they could afford, with $89 \%$ of patients either agreeing or strongly agreeing. In contrast, only $62 \%$ of patients in public answered in affirmation, with $38 \%$ of patients in the public sector disagreeing to the same proposition compared with $11 \%$ of patients in the private sector.
The patients were asked if their doctors hurried too much when treating them. Again, the private sector hospitals came trumps in this section, with $50 \%$ of patients giving a definite answer compared with $67 \%$ of patients in the public sector (Figure 11). Similarly, 65\% of patients receiving medical care in public sector hospitals said that people had to wait too long for medical care. In contrast, only $21 \%$ of private hospital patients gave a positive reply to this question. Meanwhile, in the study of Imam et al. [5], 48\% of patients felt that the waiting time for admission was lengthy after presenting to the emergency department. Lastly, 64\% of private-sector hospital patients said that they found it difficult to get an appointment right away for medical care compared with $58 \%$ of public sector patients (Figures 12 and 13).

After applying a nonparametric Pearson's Chi-square test of significance for every variable, patients' satisfaction in the private sector was found to be significantly better compared with that of public sector patients in categories of general comfort, accessibility, and technical data. However, patients in the public sector fared considerably better in the financial aspect of medical care $(p<0.05)$. In the study conducted by Khattak et al. [17], the private sector showed an overall better satisfaction in all categories except for time spent with the doctor, which was almost equal for private and public sector hospitals [5].

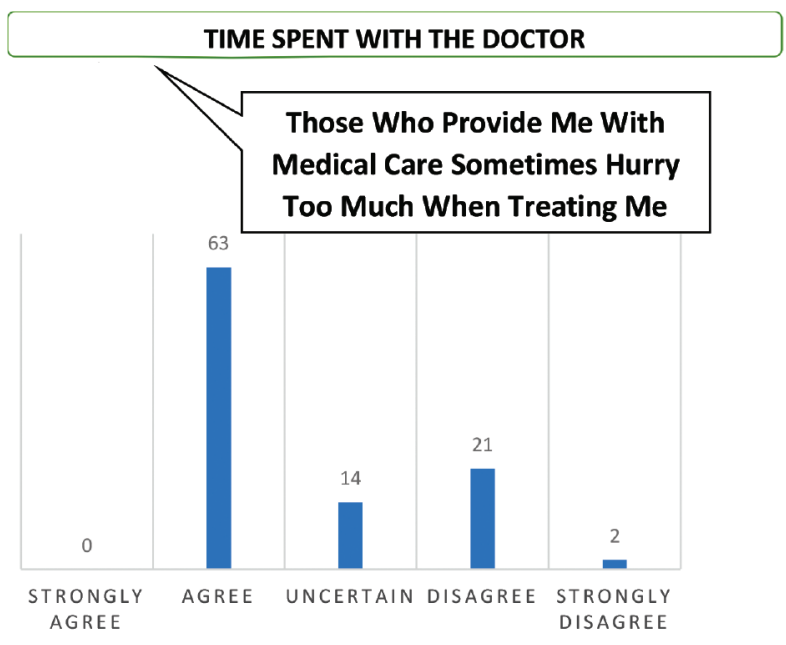

PRIVATE

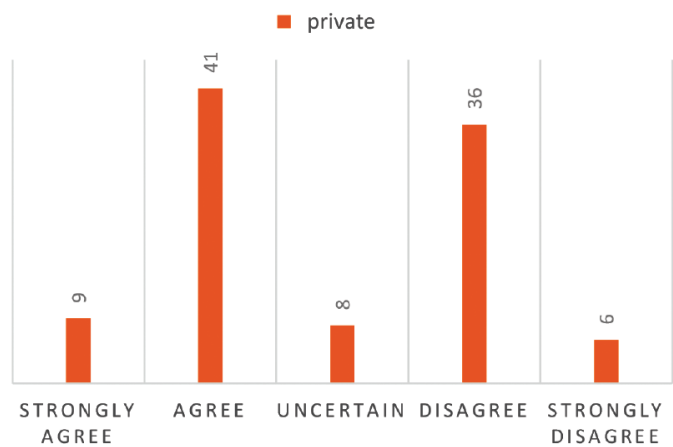

Figure 11 Sixty-three percent of patients in the public sector and $50 \%$ (including $9 \%$ of strongly agreeing patients) in the private sector indicated that the doctors sometimes hurry too much when treating them. Meanwhile, $36 \%$ of patients in private hospitals and $21 \%$ of patients in the public sector disagreed with the same proposition. 


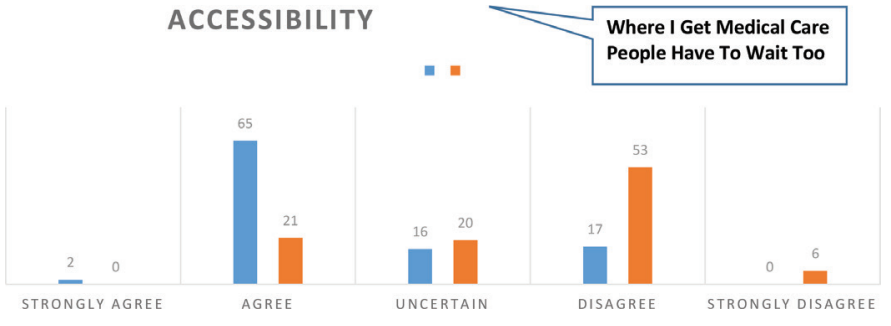

Figure 12 Sixty-seven percent of patients in public hospitals said they had to wait too long for emergency treatment. In contrast, only $21 \%$ of patients in the private sector agreed to the same question.

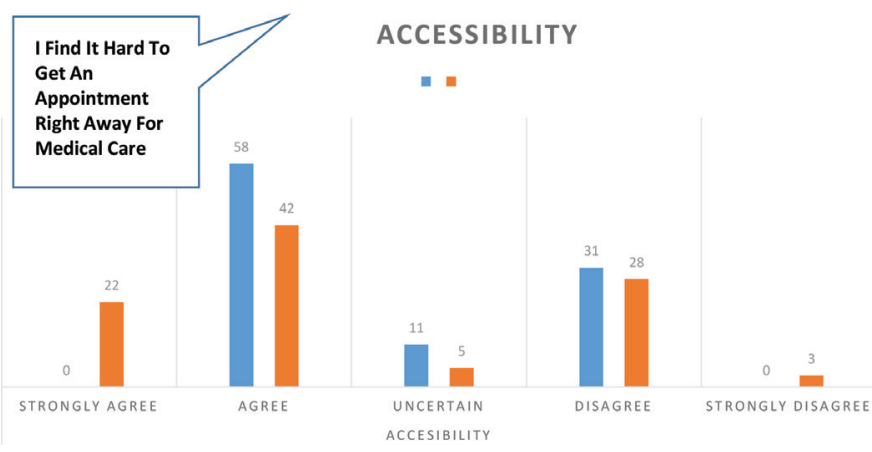

Figure 13 Fifty-eight percent of patients in the public sector and 64\% in private sector hospitals gave the response in affirmation when they were enquired about, whether they find it hard to get an appointment right away for medical care.

Although the standardized questionnaire was used, and most patient satisfaction studies were completed previously, all have a similar conclusion to ours, that is, patient satisfaction was higher in the private sector than in the public sector. However, none of the studies calculated the doctor/patient ratio in public versus private sector, and the limitations doctors and patients face in the public sector compared with those in private sector hospitals. Another possible reason may be that patients coming to private sector hospitals are more educated and perhaps have a higher level of comprehension about the disease and disease process than those who go to most public sector hospitals.

Telemedicine is a tool of the modern era. Kruse et al. [19] analyzed 44 different articles that reported patient satisfaction and concluded that telemedicine can prove to be an effective tool in providing healthcare to remote areas, with high levels of patient satisfaction but mixed levels of effectiveness and efficacy. Another study analyzed patient satisfaction and quality of care primarily in the surgical care department; it included patients who had undergone any of six major procedures including coronary artery bypass graft, hip replacement, and pulmonary lobectomy, which were adjusted for length of stay. Tsai et al.s [20] results showed that the highest patient satisfaction scores were reported in hospitals that were nonprofit and major teaching hospitals, and had a higher nurse/ census ratio [20]. Our questionnaire did not include a section on physician burnout, but a meta-analysis done revealed that physician burnout was associated with poorer quality of care, higher risk to patient safety, and poorer patient satisfaction [21]. It may be one of the reasons why patient satisfaction was higher in private sector hospitals as compared with public sector hospitals in our study, and key determinants such as time spent with the doctor were lower in public sector hospitals as compared with private sector hospitals.

\section{LIMITATIONS OF THE STUDY}

As the data were collected from four tertiary-care hospitals, results of this study cannot be generalized to the whole country. The time frame of the study and lack of resources were also limitations. The questionnaire was English based, so language barrier was also another limitation.

The patients selected for the study were not chosen through the randomized sampling process, and the element of bias could not be ruled out. Although modifications were made in the PSQ-18, there is no standardized questionnaire available for the local population.

\section{CONCLUSION}

In conclusion, patient satisfaction was higher in private hospitals than in public hospitals, with the private sector dominating in all aspects of medical care except that of finance. Specifically, patients in private sector hospitals were significantly more satisfied in terms of general satisfaction, technical data, and accessibility, whereas in finance section patients in the public sector were significantly more satisfied.

\section{RECOMMENDATIONS}

- The research was based in premier tertiary care hospitals of KPK, but there remains a lack of data on patient satisfaction on the level of primary healthcare because facilities that offer these types of services bear the larger burden in terms of patients and would reflect the actual level of patient satisfaction in terms of the whole community.

- Further research with bigger sample size is warranted.

- A new comparative study is required to evaluate patient satisfaction in public tertiary and primary healthcare levels.

- The same survey can be done to compare patient satisfaction between hospitals in two different cities.

\section{CONFLICTS OF INTEREST}

The authors declare they have no conflicts of interest.

\section{AUTHORS' CONTRIBUTION}

MJ and MSK contributed in conception and design. MJ and MSK contributed in data collection. MJ and $\mathrm{ZH}$ contributed in data analysis and interpretation, results. $\mathrm{ZH}$ and $\mathrm{MJ}$ contributed in manuscript drafting and writing. MJ, ZH and MSK contributed in language editing, appropriateness, critical revision. All authors read and approved the final version of the paper. 


\section{FUNDING}

The authors received no financial support for the research, authorship, or publication of this article.

\section{ACKNOWLEDGMENTS}

We express our great appreciation to Mohsin Zafar (Cardiology Resident, Lady reading hospital Peshawar) for their contribution, feedback, and input.

\section{REFERENCES}

[1] Bensing J. Bridging the gap. The separate worlds of evidencebased medicine and patient-centered medicine. Patient Educ Couns 2000;39;17-25.

[2] Jagadeesan R, Kalyan DN, Lee P, Stinnett S, Challa P. Use of a standardized patient satisfaction questionnaire to assess the quality of care provided by ophthalmology residents. Ophthalmology 2008;115;738.e3-43.e3.

[3] Guirguis WW, Mokhtar SA, al-Torkey MM, Khalaf AA. Patient satisfaction with hospital services: determinants and level in a hospital in Kuwait. J Egypt Public Health Assoc 1992;67;87-108.

[4] Humayun A, Fatima N, Naqqash S, Hussain S, Rasheed A, Imtiaz $\mathrm{H}$, et al. Patients' perception and actual practice of informed consent, privacy and confidentiality in general medical outpatient departments of two tertiary care hospitals of Lahore. BMC Med Ethics 2008;9;14.

[5] Imam SZ, Syed KS, Ali SA, Ali SU, Fatima K, Gill M, et al. Patients' satisfaction and opinions of their experiences during admission in a tertiary care hospital in Pakistan - a cross-sectional study. BMC Health Serv Res 2007;7;161.

[6] Zaleski P. Knights Hospitaller: the rise and fall of a chivalric order of Christian caregiving. Parabola 1990;15;55-62.

[7] Pascoe GC. Patient satisfaction in primary health care: a literature review and analysis. Eval Program Plann 1983;6;185-210.

[8] Spoeri RK, Ullman R. Measuring and reporting managed care performance: lessons learned and new initiatives. Ann Intern Med 1997;127;726-32.
[9] Ware JE, Snyder MK, Wright WR, Davies AR. Defining and measuring patient satisfaction with medical care. Eval Program Plann $1983 ; 6 ; 247-63$.

[10] Marshall GN, Hays RD. The patient satisfaction questionnaire short-form (PSQ-18). Santa Monica, CA: RAND Corporation; 1994, p. 7865.

[11] Raheem AR, Nawaz A, Fouzia N, Immamuddin K. Patients' satisfaction and quality health services: an investigation from private hospitals of Karachi, Pakistan. Res J Recent Sci 2014;3;2277-502.

[12] Irfan SM, Ijaz A, Farooq MM. Patient satisfaction and service quality of public hospitals in Pakistan: an empirical assessment. Middle East J Sci Res 2012;12;870-7.

[13] Mostafa MM. An empirical study of patients' expectations and satisfactions in Egyptian hospitals. Int J Health Care Qual Assur 2005;18;516-32.

[14] Shabbir S, Kaufmann HR, Shehzad M. Service quality, word of mouth and trust: drivers to achieve patient satisfaction. Sci Res Essays 2010;5;2457-62.

[15] Kavanaugh J, Duffy JA, Lilly J. The relationship between job satisfaction and demographic variables for healthcare professionals. Mgmt Res News 2006;29;304-25.

[16] Jawaid M, Ahmed N, Alam SN, Rizvi BH, Razzak HA. Patients experiences and satisfaction from surgical out-patient department of a tertiary care teaching hospital. Pak J Med Sci 2009;25;439-42.

[17] Khattak A, Alvi MI, Yousaf MA, Shah SZ-u-A, Turial D, Akhter S. Patient satisfaction-a comparison between public \& private hospitals of Peshawar. Int J Collab Res Internal Med Public Health $2012 ; 4 ; 713$

[18] Qidwai W, Dhanani RH, Khan FM. Implications for the practice of a patient expectation and satisfaction survey, at a teaching hospital in Karachi, Pakistan. J Pak Med Assoc 2003;53;122-5.

[19] Kruse CS, Krowski N, Rodriguez B, Tran L, Vela J, Brooks M. Telehealth and patient satisfaction: a systematic review and narrative analysis. BMJ Open 2017;7;e016242.

[20] Tsai TC, Orav EJ, Jha AK. Patient satisfaction and quality of surgical care in US hospitals. Ann Surg 2015;261;2-8.

[21] Panagioti M, Geraghty K, Johnson J, Zhou A, Panagopoulou E, Chew-Graham C, et al. Association between physician burnout and patient safety, professionalism, and patient satisfaction: a systematic review and meta-analysis. JAMA Intern Med 2018;178;1317-30. 